\title{
Dynamic problems in the operation of overresonant vibrating screens
}

\author{
Filip Matachowski ${ }^{1}$, and Stawomir Badura ${ }^{1}$ \\ ${ }^{1}$ AGH University of Science and Technology, 30-059 Kraków al.Mickiewicza 30, Poland
}

\begin{abstract}
The paper presents the results of the numerical analysis of the stress state (FEM) which is created in the construction elements of the PZ3R vibrating screen in normal operation conditions. These results where compared to and verified by tensometric, displacement and acceleration measurements. The results of strength analyses indicated the directions of possible modifications of structural elements of the screen, and also confirmed the desirability of their implementation, but in strictly specified order.
\end{abstract}

\section{Introduction}

Designing a structure is a difficult process, especially when its dynamic loads are not fully recognized, which in the next step does not allow for proper assessment of the stress in its elements.

It turns out that constructory experience is not enough for a newly designed structure to work properly, although it already has a predecessor in its class, the operation of which does not raise any objections [1].

This is the problem with the construction of the PZ3R vibrating screen, which was designed like a PZ screen, introducing changes, mainly dimensional ones, [2]. The elements of the new PZ3R screen construction began to crack after a relatively short period of device operation. The authors of the study decided to explain the reasons for this state of affairs, based on the results of analyzes of the stress state which arises in the construction elements of the vibrating screen in normal operation [3].

\section{Analysis object}

Designing a structure is a difficult process, especially when its dynamic loads are not fully recognized, which in the next step does not allow for proper assessment of the stress in its elements.

The PZ3R screen is not a classic resonance screen [4]. It differs from typical PZ screens by smaller dimensions of the sieve deck, a larger number of decks and an approximately parallel arrangement of vibrators to the sieve plates (Fig. 1). 


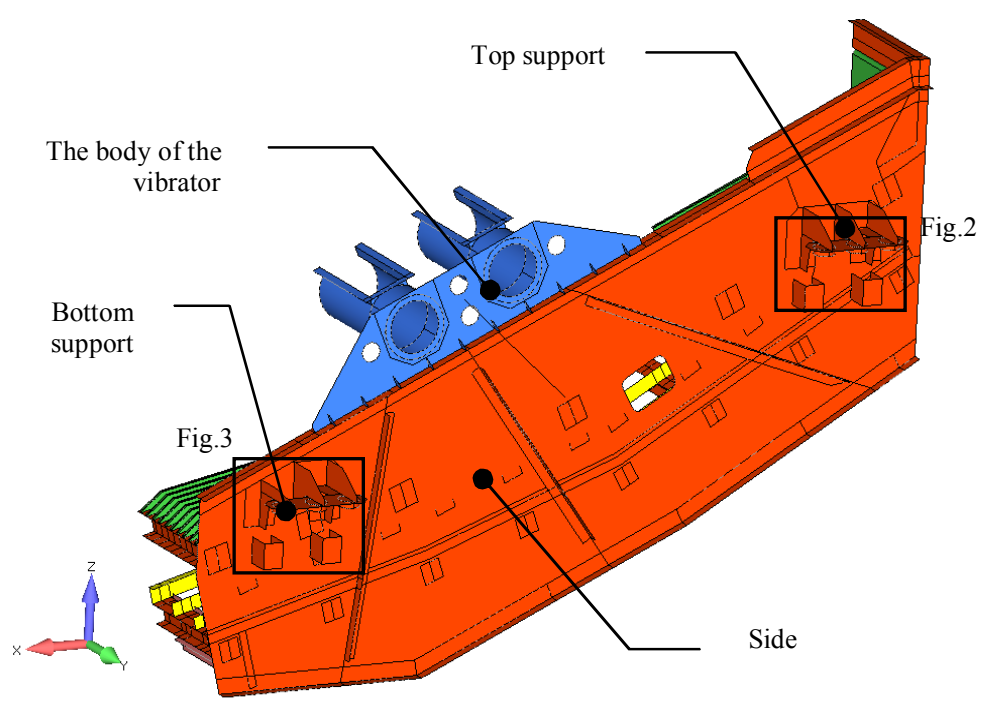

Fig. 1. Longitudinal section of the PZ3R screen - side view.

These changes have resulted in different kinematic characteristics of individual points along the length of the screen. There are vibrations from linear near the center of gravity of the vibrating screen to flattened ellipses of different inclination [5] near the supports. Three PZ3R screens were installed in one of the Polish mines for the preliminary classification of copper ore. During use, some structural elements began to break. Among others: - cracking in the area of the props of the riddle side (Fig.2),

- permanent deformation of the support (Fig.2).
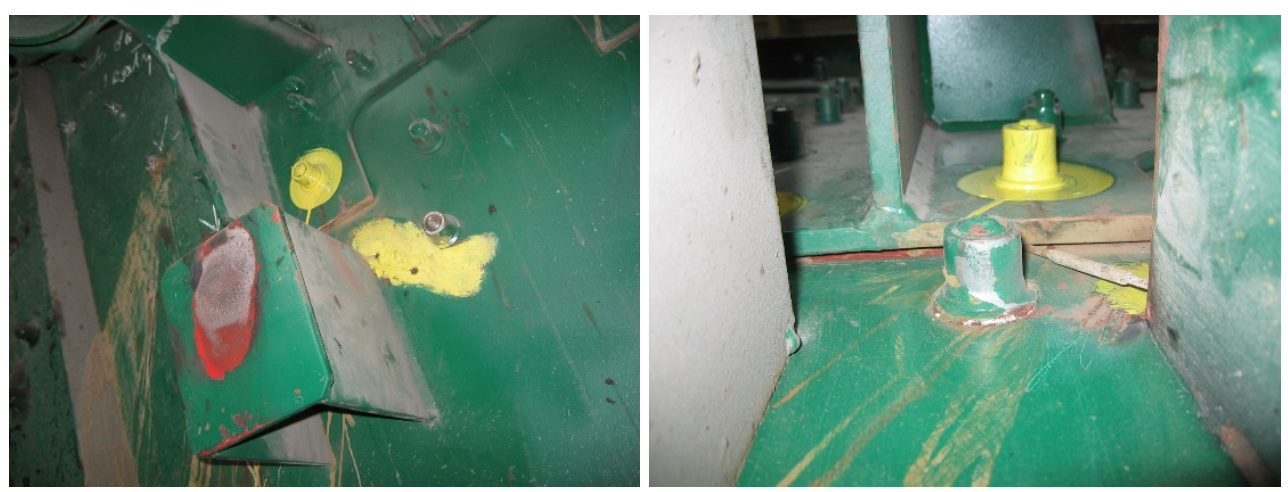

Fig. 2. Crack in the area of top support of side of the riddle (exact loaction shown on Fig.1), damage to HuckBolt screws (left picture). Permanent deformation of support (right picture).

Attempts have been made to restore the operating efficiency of the vibrating screen, by strengthening places particularly vulnerable to damage, which only temporarily reduced adverse phenomena. In order to comprehensively solve the problem, a mechanical (numerical) analysis of the screen's structural elements was performed, the results of which were verified by an experiment on the real object through tensometric measurement of strains (stresses) at the most intense points of the structure [5]. The results of these analyzes should indicate the directions of possible modernization of structural elements and, consequently, ensure full operational efficiency of the system. 
Based on the results of the strength analysis [5,6], the user introduced a number of construction changes. These changes included (Fig. 3):

- Shortening the reach (distance from side to axis of the spring) of the support by $140 \mathrm{~mm}$

- Change in the structure of the side reinforcing ribs in the top and bottom support

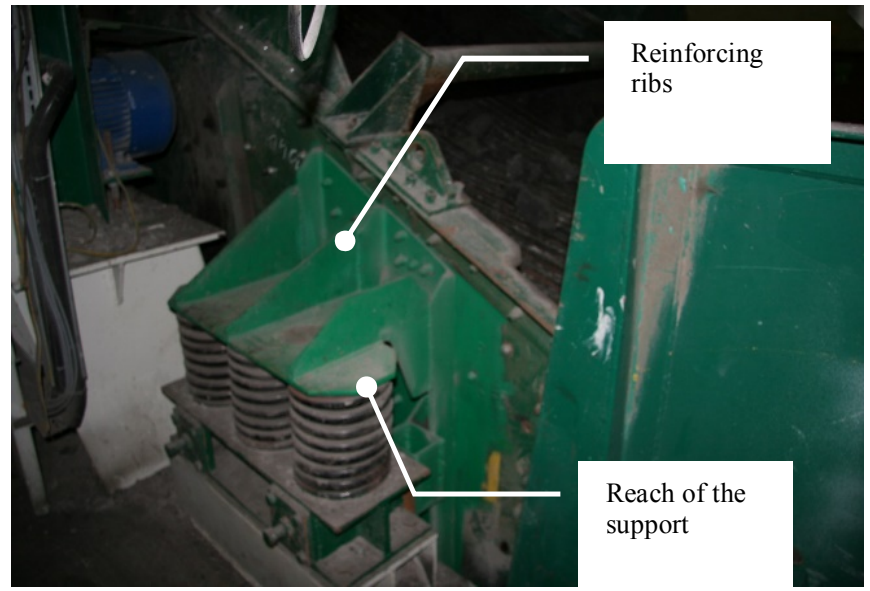

Fig. 3. View of the modified bottom support (see Fig.1 for location).

The conducted strength analysis after the changes [5] indicates the desirability of redesigning some elements of the screen, including supports. Strength analysis of the structure in which the reach of the support has been shortened by $140 \mathrm{~mm}$ indicates that the local redesign of the support does not have any significant effect on reducing the stresses in the screen structure elements. Only the solution including additionally reinforced sides of the screen with $\mathrm{C} 280$ profiles results in significant reduction of stresses in the analyzed areas of the structure [5].

\section{Analysis of the dynamics and kinematics of the vibrating screen}

As part of these tests, it was performed:

- Traces of the screen vibrations trajectory in steady and transient states [7]

- Research on vibrator self-synchronization $[8,9]$

Moreover, in the field of sieve operation dynamics, the amplitude of fixed vibrations A and the required uplift index $[4,10]$ were determined for proper operation of the vibrating screen in order to achieve the assumed capacity. The current values of these parameters are [1]:

- Vibration amplitude $A=5.6 \mathrm{~mm}$ against the required $\mathrm{A}=7 \mathrm{~mm}$

- The $\mathrm{u}_{2}=3.9$ against the required $\mathrm{u}_{2}=5.88 \div 7.67\left(\mathrm{u}_{2}\right.$ - factor which define ratio of inertia force acting on single piece of material on vibrating screen to its gravity force)

It means that the dynamics of the screen in relation to the design assumptions has significantly decreased. In order to obtain the amplitude of vibrations $A=7 \mathrm{~mm}$, the static moment of the vibrator should be increased. This change would cause the screen to operate at the maximum force, which would increase the strength problems of the structure [5]. Therefore, in relation to the construction of which the results of strength tests are described in [5], another structural change was introduced, consisting in changing the shape of the expansion beams connecting the ridding walls (Fig.1, 2 [5]). This change caused a further increase in the stiffness of the riddle. The research on the analysis of the dynamics and 
kinematics of the screen described in this study concerns a slightly different design, with a different stiffness than those described in the study [5].

\section{The effect of structural changes on the stress state}

The analysis of structural changes was made in such a way as to show the influence of each modification on the level of stress in the entire structure of the screen, which allowed to analyze its suitability.

All strength analyzes included in the study [5] were carried out taking into account the proposed modifications of the structure taking into account:

- Material changes

- Changes in support conditions

- Different load cases

The strength analyzes carried out in [5] showed a number of constructional irregularities causing concentration of stresses. For example, Figure 4 shows the concentration of stresses around the upper and lower supports.

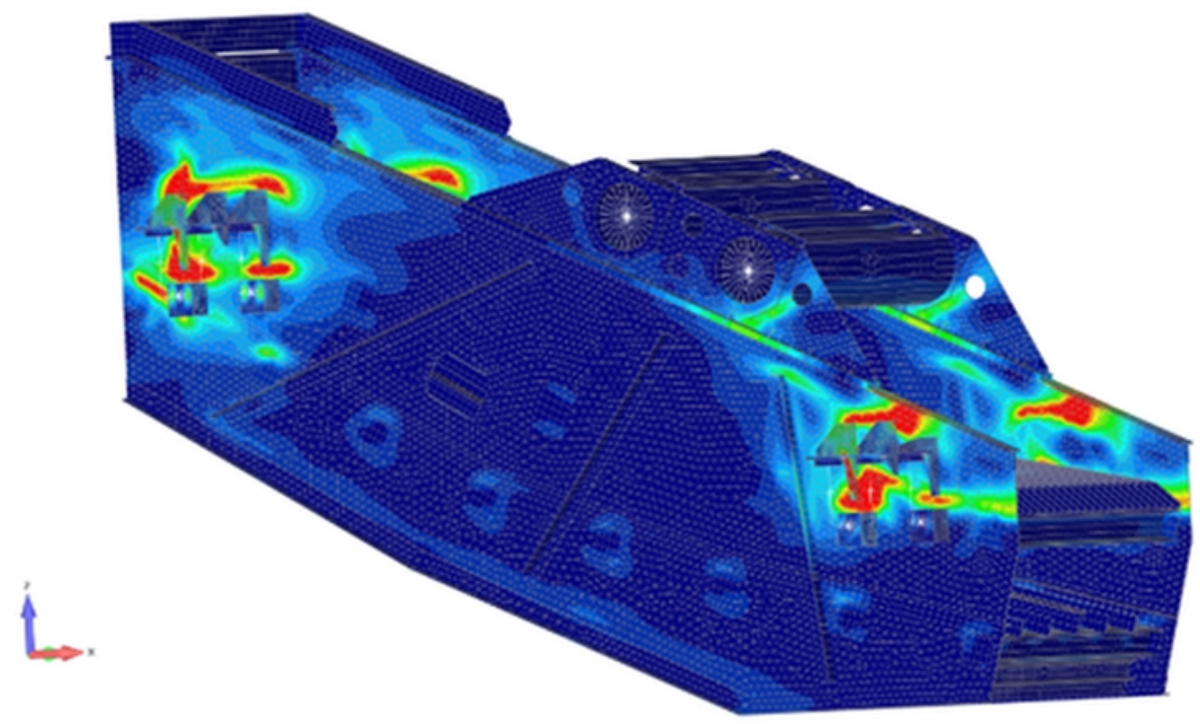

Fig. 4. Visible areas of stress concentration around supports, at the lower thrust shaft and around deck beams.

\section{Measurements of displacements, accelerations, deformations (stresses) of the actual structure of the PZ3R screen}

The obtained results of the strength (numerical) analysis were verified by measuring strains (stresses) on the real object, in the most intense points of the screen structure elements selected as a result of the numerical analysis. In addition, measurements of displacements and accelerations of selected points of the screen structure were carried out.

\subsection{Location of strain gauges on the construction of the PZ3R screen}

Tensometric rosettes were placed around the location of the bottom support of the vibrating screen, three pieces on each side of the structure. Rosettes type "delta" No. 2 and 
4 were mounted in the side part of the bottom support (Fig. 5). Rosettes "delta" type No. 1 and 3 were mounted in the bottom part of the lower supports of the vibrating screen. In the upper part of the lower legs, two-sensor rosettes No. 5 and 6 are mounted below support plate. Each measuring strain gauge was temperature compensated.

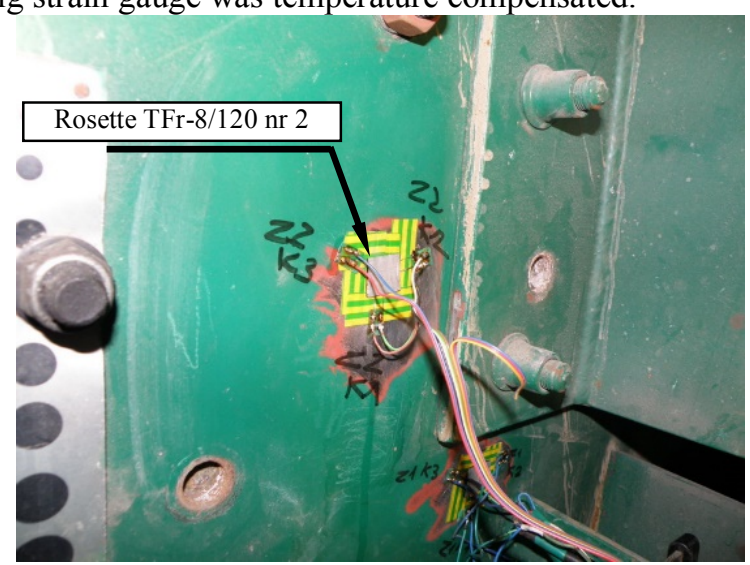

Fig. 5. Rosette No. 2 mounted in the side part of the bottom support of the vibrating screen.

During the experiment strains (stresses) of the above described points of the screen structure were made for the following phases of its operation [11]:

- Start-up,

- Steady work,

- Braking,

- Free run.

For example, in Fig. 6, the change of stress in all three phases of the screen operation registered by the No. 1 rosette, stuck - as numerical stress state analysis showed - in the area of the highest stress concentrations.

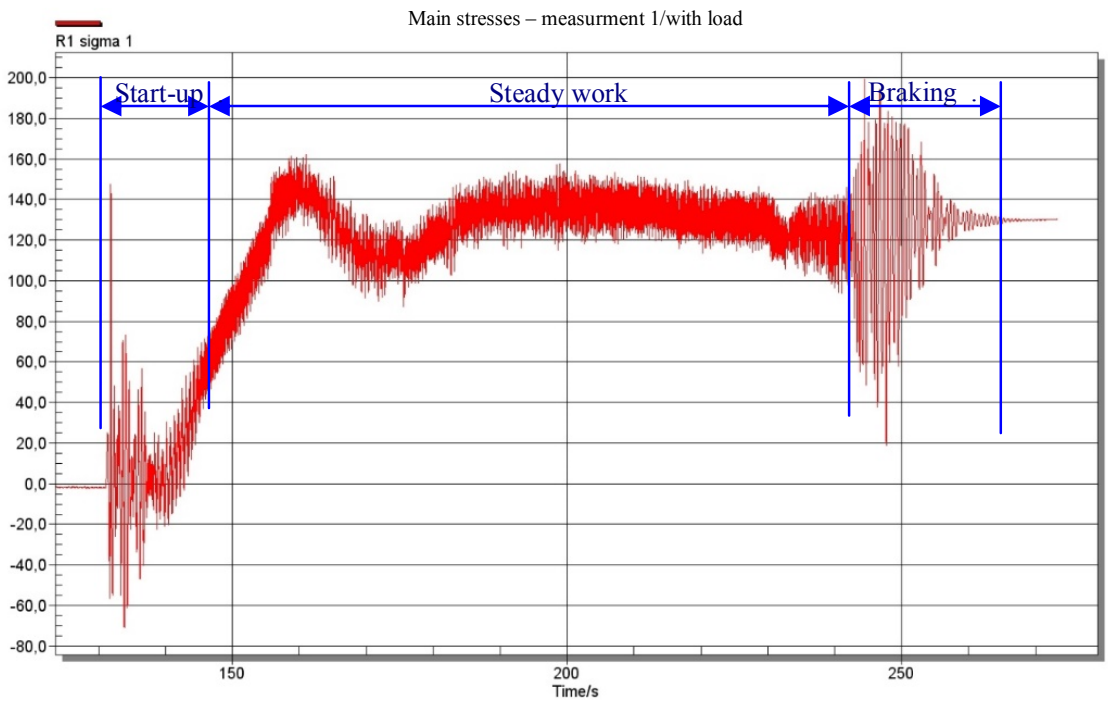

Fig. 6. Stresses $\sigma_{1}$ through the rosette No. 1 (in full service cycle).

The maximum stress values were indicated by the tensometric rosette No. 1 $\left(\sigma_{\max } \cong 190 \mathrm{MPa}\right.$ ) during system braking (Fig. 6). At the same time, the strain gauge rosette no. 2 indicated stresses $\sigma \max \cong 125 \mathrm{MPa}$. The measurements were carried out after the 
modernization described in point 2 and the obtained stress values only slightly differed from the values of stresses in specific areas of the screen structure determined by numerical analysis (FEM).

\subsection{Measurements of displacements}

Displacement measurements were carried out using HBM WA 50 inductive sensors, connected to the MGCPlus bridge. During the measurements, displacements were recorded with three sensors mounted in three mutually perpendicular planes. The measuring instruments were mounted at the bottom left support. The WA50 sensors 1 measured the vertical displacements of the screen, the sensor WA 50 No. 2 measured longitudinal horizontal displacements and the sensor WA 50 No. 3 transverse horizontal displacements (Fig. 7 and 8).

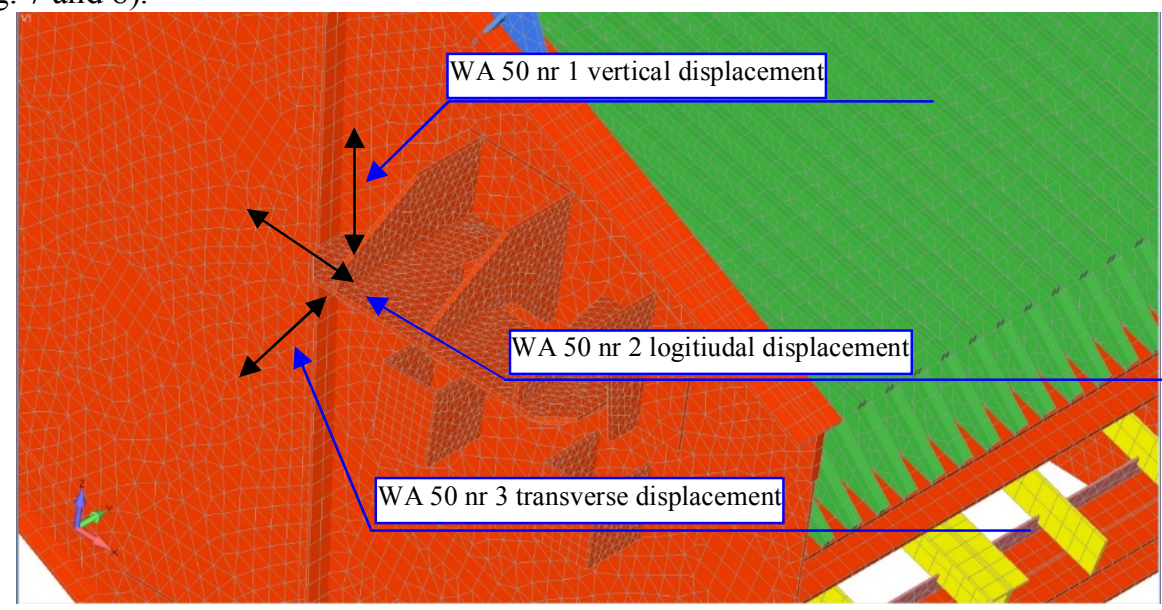

Fig. 7. Location of WA 50 displacement sensors on the left lower support of vibrating screen.

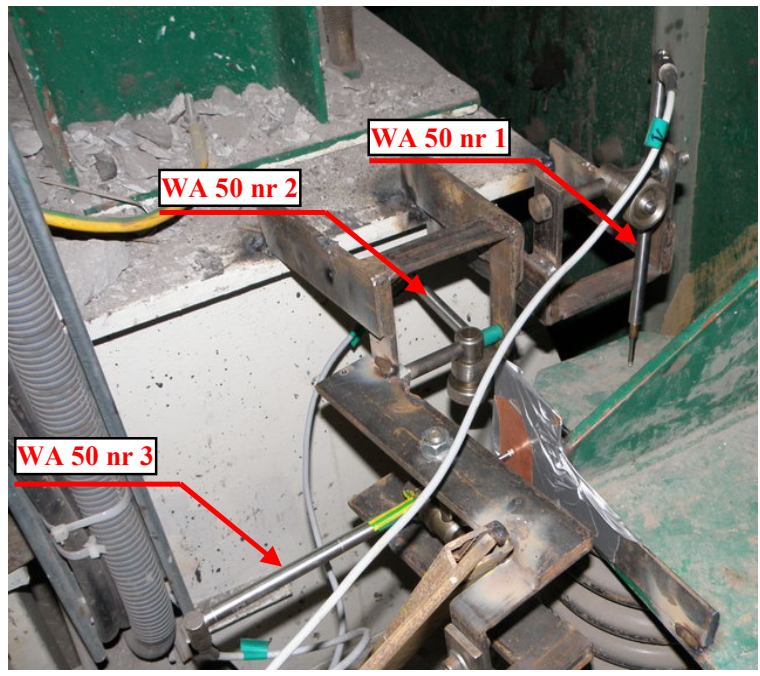

Fig. 8. WA 50 displacement sensors mounted on the vibrating screen.

The results of measurements of displacements of the indicated points of the screen structure elements, measured simultaneously with stresses, are shown in Figures 9, 10 and 11 respectively. 


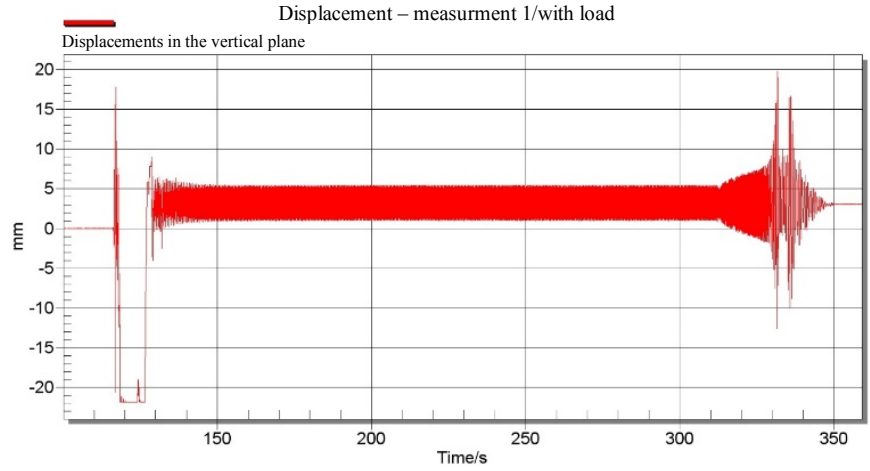

Fig. 9. Displacements in the vertical plane (with load).

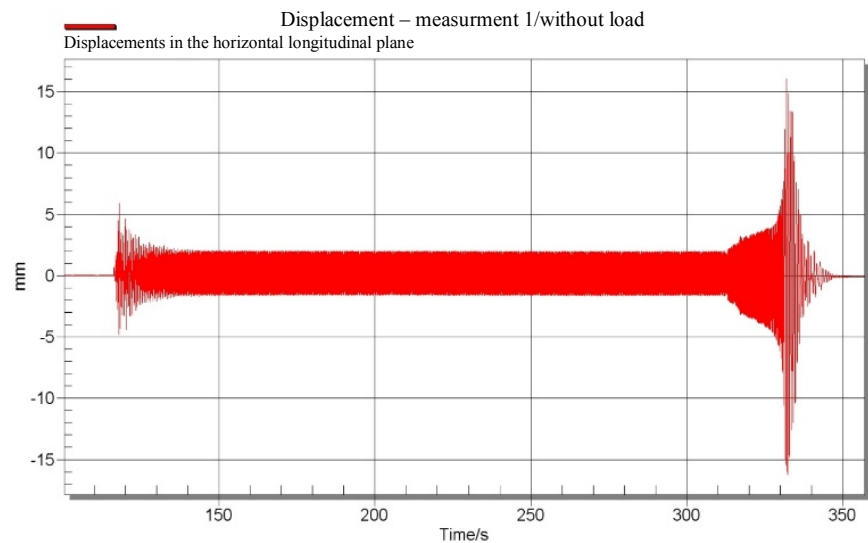

Fig. 10. Displacements in the horizontal longitudinal plane (without load).

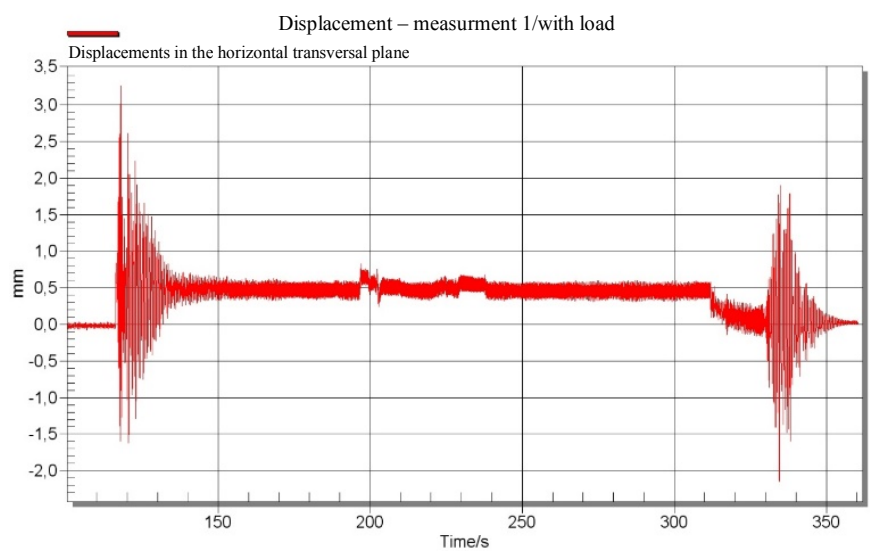

Fig. 11. Displacements in the horizontal transversal plane (with load).

The exact determination of the method of redesigning or making reinforcements in addition to the strength analysis requires the following tests:

- The correctness of self-synchronization in vibrators

- Vibration kinematics in characteristic points of the riddle

- Increase of vibration amplitude in transient states

- Observation of material flow on the sieve 
- Acceleration of the riddle in steady as well as undefined states

Conducted and described research should be helpful in the development of changes in the structure and parameters of drive of screens [11].

\section{Summary and Conclusions}

The results of the strength analysis (FEM) of the PZ3R vibrating screen construction made for the obtained maximum system load values and the results of stress measurements in the construction elements of the actual screen allow the following conclusions:

1. The stress distribution in the construction of the PZ3R vibrating screen proves that due to the assumed fatigue life the structure has significant defects $[5,12]$. The effect of these defects is the concentration of stresses mainly in the areas of supporting supports (lower and upper) and the areas of vibrator construction.

2. The occurrence of technological and welding notches in the structure is the main cause of concentration of stresses

3. Reduction of stress in the most stressed places will be obtained as a result of structural changes:

- Installation of modified lower and upper supports

- Changes in the vibrator's construction

- Conversion of some nodes and reinforcement of structural elements

\section{References}

1. J.Raszyński, K.Szczepaniak, Technical documentation. PZ3R - 2,2 x 6,0 vibrating screen, Institute of Non-Ferrous Metals in Gliwice (2005)

2. J.Raszyński, K.Szczepaniak, Technical drawings of PZ3R-2,2x6,0 vibrating screen, Institute of Non-Ferrous Metals in Gliwice (2005)

3. Workflow of PZ3R screens. Position P3/4, P3/5, P3/6, KGHM ,Rudna” (2009)

4. T.Banaszewski, Vibrating screens, Publishing house „Śląsk” (1990)

5. Report on research work Strength analysis of the PZ3R vibrating screen construction 2,2, $x$ 6,0, KWZMiK, Kraków (2009), unpublished

6. Wolny S., Banaszewski T., Dzik S., Matachowski F, Evaluation of the state of stress in structural components of a screen separator, Mechanics and Control, vol.29 no $2 \mathrm{~s} .88$ 96, (2010)

7. T.Banaszewski, A.Filipowicz, Badania poprwaności drgań przesiewaczy, Maszyny Górnicze nr.90 Gliwice (2002)

8. T.Banaszewski, Wpływ położenia samosynchronizujacych się wibratorów na drgania przesiewacza, Silesian University of Technology, Series - Mining nr.245 (2000)

9. T.Banaszewski, Wykorzystanie samosynchronizacji wibratorów do wzbudzania drgań przesiewaczy, Scientific Seminar „Aplikacje badań naukowych w budowie maszyn”; AGH Kraków (2000)

10. J.Michalczyk, T.Banaszewski, Oddziatywanie dynamiczne maszyn stosowanych $w$ przeróbce surowców mineralnych, Wydawnictwa AGH, Kraków (2006)

11. Report on research work Analysis of the work dynamics of the PZ3R vibrating screen and development of guidelines for introducing structural changes, KWZMiK WIMiR AGH, Kraków (2009) unpublished

12. Polish norm PN-90/B-03200 „Konstrukcje stalowe. Obliczenia statyczne $i$ projektowanie" 